\title{
ЗЕЛЕНАЯ ХИМИЯ: ПРИНЦИП И ЕГО ПРИМЕНЕНИЕ
}

\author{
Али Яр Джавад, магистрант ФГБОУ ВО Астраханский государственный университет, \\ Российская Федерачия, г. Астрахань
}

\section{DOI: https://doi.org/10.31435/rsglobal_conf/30052021/7580}

\begin{abstract}
Green Chemistry is the design of chemical processes and products which reduce or eliminate the use and generation of toxic, poisonous, hazardous and bio-accumulative chemical substances. It is a new approach to scientifically based environmental protection and play a vital role in controlling global warming, acid rain and climate change. Its principle plays a fundamental tool in pollution prevention, increasing efficiency, selectivity and minimizes waste production. The scope of Green Chemistry is predicated on, but not limited to, the definition proposed by Anastas and Warner (Green Chemistry: Theory and Practice, P T Anastas and J C Warner, Oxford University Press, Oxford, 1998). Green chemistry is the utilisation of a set of principles that reduces or eliminates the use or generation of hazardous substances in the design, manufacture and application of chemical products. The Green Chemistry and Commerce Council (GC3) was formed in 2005 and provides an open forum for participants to debate and share information and experiences concerning advancing green chemistry and style for the environment because it pertains to sustainable supply chain management. In 1998, principles of Green chemistry outlined, ask chemists to stop waste, minimize energy use, use renewable raw materials, design biodegradable products, and choose chemicals to attenuate potential accidents.
\end{abstract}

Keywords: Green Chemistry, Hazardous Substances, Waste production, Environmental protection, GC3.

Введение. Зеленая химия - это донаучный подход к разработке химических процессов и продуктов, которые сокращают или исключают антропогенное использование и образование опасных, токсичных и биоаккумуляционных химических веществ. Это означает разработку материалов, содержащих химические вещества, которые будут использоваться в будущем и будут лучше для здоровья человека и окружающей среды. Это помогает ученым и исследователям создать эффективную планету, на которой человек использует все в рамках биогеохимического цикла, так что жизнь каждого человека будет лучше и будет обеспечено устойчивое развитие. Зеленая химия отличается от химии окружающей среды, потому что химия окружающей среды определяет источник, разьясняет механизм и количественно определяет проблемы в окружающей среде Земли, в то время как зеленая химия ищет эти экологические проблемы, создавая альтернативные и безопасные технологии $[4,6]$. Зеленая химия для химического синтеза решает наши будущие проблемы в работе с химическими процессами и продуктами путем изобретения новых реакций, которые позволят максимально увеличить количество указанных продуктов и минимизировать побочные продукты, разработать новые схемы и устройства синтеза, которые упростят операции в химическом производстве, и изыскать более экологичные растворители, экологически безвредны по своей природе. Наши будущие задачи в области ресурсной, экологической, экономической и социальной устойчивости требуют более эффективных и безопасных научных технологий для работы с химическими процессами и продуктами. Зеленая химия применяется на протяжении всего жизненного цикла химического продукта, включая его проектирование, производство, использование и полную утилизацию. Калифорнийская инициатива по зеленой химии (CGCI) может быть инициативой из шести частей по снижению воздействия токсинов на население и окружающую среду за счет улучшения знаний и регулирования химических веществ; две части стали статутом в 2008 году. Зеленая химия эффективно использует (предпочтительно возобновляемое) сырье, устраняет Отходы и избегают использования токсичных и / или опасных реагентов и растворителей при производстве и применении химических продуктов. Совет по зеленой химии и торговле (GC3) был сформирован в 2005 году и представляет собой открытый форум для участников для обсуждения и обмена информацией и опытом в отношении продвижения зеленой химии и стиля для окружающей среды, поскольку это относится к устойчивому управлению цепочкой поставок. Зеленая химия это междисциплинарная область, основанная на знаниях из химии, химической инженерии, токсикологии и экологии. Зеленая химия обещает сократить ущерб здоровью и окружающей среде. В прошлом мы сосредоточились на очистке от токсичных загрязнений, возможно, это было движение к химическим веществам, которые были бы более безопасными для окружающей среды 
и человека. Исследователи экологической химии разрабатывают новые катализаторы, тестируют новые растворители и экспериментируют с процессами микро масштабного потока. Возможно, лучше остановить отходы, чем обрабатывать или упаковывать отходы после того, как они образовались. Синтетические методы должны быть разработаны таким образом, чтобы обеспечить максимальное включение всех материалов, используемых в методе, в конечный продукт. Синтетические методы должны быть разработаны таким образом, чтобы использовать и производить вещества, которые обладают незначительной токсичностью для здоровья человека и, следовательно, окружающей среды, или не имеют ее вообще. Химические продукты должны быть разработаны таким образом, чтобы повышать эффективность и уменьшать количество загрязняющих веществ. По возможности следует избегать использования вспомогательных веществ (например, растворителей, разделительных агентов и т. д.). Энергия должна быть сведена к минимуму. Вот температура и давление надо понижать. Везде, где это технически и экономически целесообразно, используются возобновляемые ресурсы. Сокращение производных финансовых инструментов следует избегать ненужных производных финансовых инструментов. Каталитические реагенты (насколько возможно селективные) превосходят стехиометрические реагенты. Побочные продукты не должны разрушать окружающую среду и распадаться на безвредные продукты разложения. Мы всегда должны контролировать и контролировать до образования опасных веществ. Химические изменения следует выбирать, чтобы снизить вероятность химических аварий, таких как пожары и взрывы [2,5,7]. Есть ли способ лучше? Действительно, есть. Лучше всего практиковать зеленую химию [8].

Основы зеленой химии.

Три основных точки, касающиеся рамок зеленой химии, можно резюмировать следующим образом:

1. Зеленая химия проектирует на всех этапах химического жизненного цикла.

2. Зеленая химия стремится спроектировать свойственный природу химических продуктов и процессов, чтобы уменьшить их присущий опасность.

3. Зеленая химия работает как связная система принципов или критериев проектирования [11].

\section{2 принципов зеленой химии.}

Зеленая химия - это концепция, которая использует 12 конкретных принципов для получения более безопасных, менее опасных и более эффективных продуктов при меньшем количестве отходов. Принципы были разработаны Полом Т. Анастасом и Джоном К. Уорнером в 1991 году [10].

1. Лучше предотвратить потери, чем перерабатывать и чистить остатки.

2. Методы синтеза надо выбирать таким образом, чтобы все материалы, использованные в процессе, были максимально переведены в конечный продукт.

3. Методы синтеза по возможности следует выбирать так, чтобы используемые и синтезируемые вещества были как можно менее вредными для человека и окружающей среды.

4. Создавая новые химические продукты, надо стараться сохранить эффективность работы, достигнутую ранее, при этом токсичность должна уменьшаться.

5. Вспомогательные вещества при производстве, такие как растворители или разделяющие агенты, лучше не использовать совсем, а если это невозможно, их использование должно быть безвредным.

6. Обязательно следует учитывать энергетические затраты и их влияние на окружающую среду и стоимость продукта. Синтез по возможности надо проводить при температуре, близкой к температуре окружающей среды, и при атмосферном давлении.

7. Исходные и расходуемые материалы должны быть возобновляемыми во всех случаях, когда это технически и экономически выгодно.

8. Где возможно, надо избегать получения промежуточных продуктов (блокирующих групп, присоединение и снятие защиты и т.д.).

9. Всегда следует отдавать предпочтение каталитическим процессам (по возможности наиболее селективным).

10.Химический продукт должен быть таким, чтобы после его использования он не оставался в окружающей среде, а разлагался на безопасные продукты. 
11.Нужно развивать аналитические методики, чтобы можно было следить в реальном времени за образованием опасных продуктов.

12.Вещества и формы веществ, используемые в химических процессах, нужно выбирать таким образом, чтобы риск химической опасности, включая утечки, взрыв и пожар, были минимальными [1,9].

12 принципов зеленой химии, изложенные в 1998 году, просят химиков прекратить отходы, минимизировать потребление энергии, использовать возобновляемое сырье, разрабатывать биоразлагаемые продукты и выбирать химические вещества для уменьшения потенциальных аварий. Но реализация этих принципов на практике часто требует компромиссов, особенно когда вы пытаетесь проработать «зелень» всего процесса. Благодаря использованию этого нового пути затраты были снижены на $60 \%$, и, следовательно, выход продукта увеличился с $59 \%$ до $81 \%$. РАСТВОРИТЕЛЬ: Развитие зеленой химии переопределяет роль растворителя: идеальный растворитель облегчает массоперенос, но не т растворяться! Кроме того, желательный зеленый растворитель должен быть натуральным, нетоксичным, дешевым и легкодоступным. Более желательно, чтобы он обладал дополнительными преимуществами, способствующими реакции, разделению или рециркуляции катализатора. Зеленые растворители - это экологически чистые растворители или биорастворители, полученные при обработке сельскохозяйственных культур. Использование нефтехимических растворителей является ключом к большинству химических процессов, но не без серьезных последствий для окружающей среды [3,7].

- Вода: единственный естественный растворитель на Земле - это вода. Жизнь требует развития химических связей в водной среде. Использование воды в качестве растворителя также подразумевает устранение утомительных процессов защиты-снятия защиты, безусловно, кислых водородсодержащих функциональных групп, что способствует общей синтетической эффективности [7]. Многие химические и биохимические реакции происходят в воде в окружающей среде [8].

- $\mathbf{C O}_{2}$ : Особенностью жидкого и сверхкритического $\mathrm{CO}_{2}$ является его высокая смешиваемость с газами, что обеспечивает высокую эффективность (и часто более высокую селективность) в таких реакциях, как гидрирование с газообразным водородом и окисление с воздухом. Другой особенностью $\mathrm{CO}_{2}$ является его быстрое отделение от катализаторов и продуктов путем простого сброса давления и повторного улавливания. Проведенный в 2007 году анализ экологически чистых растворителей, влияющих на жизненный цикл, оценивает воду и сверхкритический $\mathrm{CO}_{2}$ как многообещающие экологически чистые альтернативы традиционным органическим растворителям.

Биокатализ: зеленая химия встречается с белыми биотехнологиями.

Высокая активность и хемоселективность, избирательность по регионам, стереоселективность достигаются в реакциях многофункциональных молекул без необходимости активации функциональных групп и защиты, часто требуемых в традиционных органических синтезах. Иллюстративные примеры представлены заменой классических химических процессов ферментативными аналогами в синтезе полусинтетических пенициллинов и цефалоспоринов.

Примеры зеленой химии и стиля для успеха в защите окружающей среды

1. Более простое средство пожаротушения, устраняющее галогены и использующее воду вместе со сложным поверхностно-активным веществом.

2. Удаление мышьяка из консервантов древесины, используемых в древесине для настилов и игрового оборудования.

3. Автомобильные покрытия с более высокими эксплуатационными характеристиками, которые удаляют значительное количество свинца и заменяют его относительно безвредным элементом иттрием.

4. С 1996 по 2008 годы проекты, получившие президентскую награду EPA Green Chemistry: устранено более 1,1 миллиарда фунтов опасных химикатов и растворителей. $f$ Снижение выбросов в атмосферу почти 400 миллионов фунтов $\mathrm{CO}_{2} . f$ Сэкономлено более 21 миллиарда галлонов воды. 
5. Использование этикетки dfe на около 1000 продуктов, состав которых изменен таким образом, чтобы сделать их экологически безопасными, конкурентоспособными и эффективными, представляет собой скидку в размере 270 миллионов фунтов стерлингов на вызывающие озабоченность химические вещества.

6. Признание EPA 40 чемпионов (высший уровень) и 22 партнеров, которые взяли на себя обязательство использовать более безопасные поверхностно-активные вещества в рамках Инициативы по более безопасным моющим средствам.

7. Благодаря проведенному Агентством по охране окружающей среды анализу альтернатив с участием многих заинтересованных сторон, отрасли промышленности перешли на использование более безопасных антипиренов в мебели и сократили использование свинца в электронике. Анализ также предоставил информацию о средствах индивидуальной защиты и методах управления, направленных на минимизацию рисков, связанных с химическим воздействием в центрах ухода за ногтями.

Методы для государств по продвижению зеленой химии и стиля для окружающей среды

Калифорнийская инициатива по зеленой химии.

Роль образовательных учреждений Образовательные учреждения играют жизненно важную роль в продвижении подходов GC и dfe посредством:

- Обучение долгосрочной рабочей силы зеленой экономики.

- Открытие новой зеленой химии и вариантов товаров.

- Поддержка усилий по преодолению прикладных проблем.

- Анализ вариантов политики.

- Использование возобновляемых ресурсов: Фторид, никель Рания и, следовательно, Cs зеленого синтеза являются катализаторами, которые будут извлекаться и повторно использоваться повторно.

- Никель Ренея может быть твердым катализатором из никелево-алюминиевого сплава. Пористая структура катализатора возникает в результате селективного удаления алюминия из частиц сплава с использованием концентрированного раствора едкого натра по следующему химическому уравнению:

$$
2 \mathrm{Al}+2 \mathrm{NaOH}+6 \mathrm{H}_{2} \mathrm{O} \longrightarrow 2 \mathrm{Na}\left[\mathrm{Al}(\mathrm{OH})_{4}\right]+3 \mathrm{H}_{2}
$$

- Палладий может быть серебристо-белым металлом. Он обычно используется в каталитических нейтрализаторах. Палладий дополнительно используется в электронике, стоматологии, медицине, водороде.

- Очистка, химические применения и обработка грунтовых вод. Его часто перерабатывают из списанных каталитических нейтрализаторов.

Последние изменения в зеленой химии: законодательство

В апреле 2007 года Калифорнийское агентство по охране окружающей среды $(\mathrm{Cal} /$ EPA) начало инициативу «Зеленая химия» для продвижения инноваций, создания новых рабочих мест и защиты людей от вредных веществ. После сбора мнений более 600 участников, включая лидеров отрасли, общественных организаторов и ученых, Калифорнийское агентство по охране окружающей среды / ЕРА разработало ряд способов уменьшения воздействия токсичных химикатов на людей и окружающую среду. В сентябре 2008 года, следуя совету $\mathrm{Cal}$ / ЕРА, законодательный орган Калифорнии принял два знаменательных законопроекта, направленных на продвижение зеленой химии. Калифорния была первым штатом, в котором была принята всеобъемлющая политика «зеленой химии».

\section{Мировые инициативы в правительстве и академических кругах}

Неотъемлемым компонентом роста зеленой химии является распространение образования и исследований в области зеленой химии. С этой целью несколько университетов по всему миру создали специальные кафедры, специализирующиеся на преподавании, изучении и расширении зеленой химии [7].

Заключение. Зеленая химия решает такие проблемы, изобретая новые реакции, которые позволят максимизировать желаемые продукты и свести к минимуму побочные 
продукты, разрабатывая новые синтетические схемы и видения, которые упростят операции в химическом производстве, и изыскивая более зеленые растворители, которые по своей природе экологически и экологически безвредны. Применения 12 руководящих принципов можно найти как в малых, так и в огромных масштабах: от выбора ингредиентов для реакций, которые минимизируют отходы и риски, до показателей, позволяющих количественно определять отходы и эффективность процесса. Зеленая химия представляет собой уникальный форум для публикации инновационных исследований о других зеленых и устойчивых технологиях.

\section{ЛИТЕРАТУРА}

1. А.В. Великородов, А.Г. Тырков. ЗЕЛЕНАЯ ХИМИЯ. МЕТОДЫ, РЕАГЕНТЫ И ИННОВАЦИОННЫЕ ТЕХНОЛОГИИ. 2010. 258c.17-18c.

2. Горячева В.А., Христофорова И.А.,ЗЕЛЕНАЯ ХИМИЯ И УСТОЙЧИВОЕ РАЗВИТИЕ.

3. Anita Ivanković ${ }^{1}$, Ana Dronjić ${ }^{1}$, Anita Martinović Bevanda ${ }^{2}$, Stanislava Talić $/ /$ Review of 12 Principles of Green Chemistry in Practice. 2017; 6(3): 39-48, http://www.sciencepublishinggroup.com/j/ijsge, doi: 10.11648/j.jijse.20170603.12

4. Hosam El-Din Mostafa Saleh and M. Koller// Principles of Green Chemistry, http://dx.doi.org/10.5772/intechopen.71191. 2018. p.14.

5. James H. Clark// Green chemistry: challenges and opportunities, Green Chemistry February 1999. p.8

6. Mohd Wahid, Faizan Ahmad, Nafees Ahmad, Green Chemistry: Principle and its Application// https://www.researchgate.net/publication/322078077, 2nd July 2017 ISBN: 978-81-934083-6-0. pp. 365-399.

7. Sandhya S. Ahire, Sujeetkumar I. Ahire and Suyog Chaudhari, GREEN CHEMISTRY// www.wjpps.com, Vol 10, Issue 4, 2021. DOI: 10.20959/wjpps20214-18633

8. Stanley E. Manahan, Green Chemistry and the Ten Commandments of Sustainability 2nd ed. ChemChar Research, Inc Publishers Columbia, Missouri U.S.A.2006. http://www.chemchar.com

9. Karen Peabody O'Brien, Shari Franjevic and Julie Jones Advancing Green Chemistry // Green Chemistry and Sustainable Agriculture: The Role of Biopesticides. 2009.p.55

10. Statement on green chemistry, https://ebookpdf.com/anastas-p-t-warner-j-c-green-chemistry-theory-andpractice-oxford-univ-press-1998

11. Paul Anastas and Nicolas Eghbali, Green Chemistry: Principles and Practice, Chem. Soc. Rev., 2010, 39, 301-312 